\title{
O PERFIL DAS DISCIPLINAS DE HANDEBOL DAS INSTITUIÇÕES DE ENSINO SUPERIOR
}

Heloisa Helena Baldy Reis*

Rafael Moreno Castellani**

\section{RESUMO}

O objetivo deste artigo é apresentar uma pesquisa sobre o perfil das disciplinas de handebol oferecidas pelas Instituições de Ensino Superior brasileiras a partir da visão de seus professores. Foi aplicado um questionário contendo 10 perguntas. As mesmas continham elementos que permitiam caracterizar os traços gerais do perfil dos professores(as) e das disciplinas de handebol. Os resultados apontaram que a maioria dos 43 professores já foram handebolistas, possuem formação de especialistas ou mestres e lecionam nos cursos de licenciatura. Os perfis dos cursos diferem entre si numa série de aspectos: número de disciplinas, carga horária, alunos matriculados, conteúdos ensinados e métodos de ensino. A pesquisa ratifica a importância e necessidade de cursos de atualização para esse público.

Palavras-Chave: Perfil dos Professores de Handebol e do conhecimento tratado na formação inicial; Handebol; Formação profissional; graduação em Educação Física;

\section{INTRODUÇÃO'}

A Confederação Brasileira de Handebol (CBH) organiza anualmente o Encontro Nacional de Professores de Handebol das Instituições de Ensino Superior Brasileiras (ENPH-IESB). Este tem por objetivo promover o debate referente aos conhecimentos existentes e produzidos acerca do handebol, assim como as pesquisas realizadas nas diversas IESB cujo foco seja a modalidade esportiva Handebol, por meio de palestras e apresentações de trabalhos em formato de pôster e apresentação oral.

\footnotetext{
"Professora do Programa de Pós-graduação da Faculdade de Educação Física UNICAMP.

**Mestre em Educação Física pela Universidade Estadual de Campinas.

${ }^{1}$ Os procedimentos empregados na pesquisa estão de acordo com os princípios éticos norteadores das Resoluções 196/96 e 251/97 do Conselho Nacional de Saúde.
} 
É notório que pelas dimensões continentais do Brasil e pela grande quantidade de IES espalhadas pelo território nacional, encontraríamos uma significante variação das condições e estruturas destas instituições assim como das características e qualidades das disciplinas de handebol que elas oferecem. Diante disso, este artigo teve por objetivo apresentar resultados de uma pesquisa que analisou o perfil das disciplinas de handebol que são oferecidos pelas IES brasileiras a partir do depoimento de seus professores. Para tal finalidade tomamos como referência as informações trazidas pelos professores participantes do II Encontro Nacional de Professores de Handebol, representando a universidade a qual lecionam. Nossa análise se fundamentou na caracterização do corpo docente dessas Instituições de Ensino Superiores (IES), na estrutura e condição oferecidas aos docentes das disciplinas de Handebol, nos conteúdos ensinados e por fim no perfil dos cursos oferecidos aos estudantes de Educação Física destas Instituições.

Corroboramos com Tardif (2002 apud SOUZA, 2007, p. 54) quando este alega que:

\begin{abstract}
A oposição tradicional em ñeoria e práticaòé muito pouco pertinente e demasiadamente simplificadora no que se refere aos aspectos epistemológico e conceitual. A pesquisa universitária na área da educação e a práticas do ofício de professor não são regidas pela relação entre teoria e prática, pois ambas são portadoras e portadoras de práticas e de saberes, de teorias e de ações, e ambas comprometem os atores, seus conhecimentos e suas subjetividades. Nessa perspectiva, a relação entre a pesquisa universitária e o trabalho docente nunca é uma relação entre uma teoria e uma prática, mas uma relação entre atores, entre sujeitos cujas práticas são portadoras de saberes.
\end{abstract}

Sendo assim, nossa pesquisa partiu da compreensão de que os professores de ensino superior das disciplinas historicamente referenciadas como ñpráticasòdeveriam ter conhecimentos atuais sobre o esporte, didática e ensino, serem sujeitos ativos e considerar sua sala de aula como uma possibilidade de organização, produção e transmissão de saberes historicamente produzidos sobre o tema da disciplina. Desta forma cabe a ele buscar restratégias de ensino que possibilitem ao aluno uma aproximação dos fundamentos técnico-táticos essenciais para a aprendizagem de cada modalidade esportivaò(SOUZA, 2007, p. 131). 
A partir da compreensão do papel do professor exposta, buscou-se na elaboração do instrumento de pesquisa perguntas para além da caracterização dos professores e instituições. Perguntou-se sobre as estratégias metodológicas que eles utilizavam para ensinar o graduando a ensinar handebol. Como é sabido, todos os participantes do curso ensinam seus alunos graduandos (primeiramente) a jogar handebol ${ }^{2}$, para a partir desse procedimento pedagógico, problematizar e criar elementos que fundamentarão o ensino de seus graduandos, quando estes ocuparem posições de docentes, sendo assim, o questionário apresentou as seguintes alternativas: método parcial, método global, método misto, iniciação esportiva universal (IEU) ${ }^{3}$, outro. Neste último, havia um espaço para a denominação de outro método de ensino-aprendizagem ou outras observações pertinentes à questão.

Corroboramos com Schön (1992 apud SOUZA, 2007: 134) ao entendermos que:

O professor enfrenta em sua formação um conflito de valores, o qual, na Educação Física, se remete à vivência e formação baseada na teoria tradicional (tecnicista) e às novas teorias críticas (progressistas) as quais a maioria dos cursos de formação tem como orientação de seus currículos.

Em outra questão buscou-se saber quais os conteúdos que eles ensinavam em suas aulas de handebol, tendo como alternativas: fundamentos do handebol, postos específicos de pontas e pivô, postos específicos de armadores, posto específico de goleiro, regras, histórico, meios táticos

\footnotetext{
${ }^{2}$ Informação obtida dos professores durante o evento que se realizou a pesquisa, conforme já mencionado no primeiro parágrafo da introdução deste artigo o objetivo do encontro de professores de handebol de IES é ñpromover o debate referente aos conhecimentos existentes e produzidos acerca do handebolò

${ }^{3}$ O IEU é uma proposta metodológica que se apoia em métodos de ensino que combinam aprendizagem incidental e intencional a partir de situações de jogos, esta ficou conhecida pela comunidade do handebol como um método de ensino dos esportes coletivos, por isto a escolha de chama-la de método de ensino em nosso questionário, o que tínhamos de fato como intenção na elaboração do questionário era diferenciar métodos tradicionalmente conhecidos no subcampo, tais como: método parcial, misto, global dos métodos que se utilizam da coordenação e das situações de jogo. Neste sentido, a denominação de r̃métodoòlEU possibilitou a compreensão da questão aos nossos entrevistados, não havendo prejuízo quanto a imprecisão do uso de método para IEU ao invés de procedimento metodológico ou mesmo método situacional, como hoje é conhecido.
} 
defensivos, meios táticos ofensivos, sistemas defensivos, sistemas ofensivos, periodização do treinamento em handebol, mini-handebol, handebol de praia. Nas alternativas sobre os meios táticos e sistemas foram solicitadas as especificações de quais seriam esses com o objetivo de analisar se os professores das IES tem conhecimento da produção acadêmica veiculada na literatura sobre sua disciplina.

Segundo Souza (2007: 135), para o ensino dos esportes, são necessários:

\begin{abstract}
Conhecimento histórico-social do esporte;
Definição e caracterização das manifestações do esporte: rendimento/lazer/educacional;

Problematização do ensino buscando superar os entraves de sua prática: exclusão, discriminação, superação a qualquer custo, questões de gênero, etc.;

Instrumentalização através de novas metodologias/tecnologias de ensino;

A busca por um referencial teórico, a realização de pesquisas em ambiente escolar que subsidiem a prática pedagógica;

A preocupação com o aprendizado individual e coletivo, considerando que, como ser social e cultural, o aluno já possui um conhecimento adquirido pelas relações que se estabelecem ao longo de sua vida;

Considerar as dimensões: procedimental, atitudinal e conceitual durante o processo de planejamento e prática pedagógica;

Considerar a influência da mídia no desenvolvimento pessoal e coletivo dos indivíduos.
\end{abstract}

A pesquisa de Reis (1995) sobre a literatura do ensino dos esportes coletivos produzida até 1994 apontou para uma proposta de ensino tradicional e tecnicista voltada para a fragmentação do conteúdo e para a mecanização de ações táticas específicas independentemente da leitura do jogo. Considerando que a última década do Século $X X$ e a primeira do $X X I$ foram férteis na produção e veiculação de pesquisas e propostas de ensino dos esportes coletivos baseadas em conhecimentos cognitivos, nos interessamos em pesquisar o grupo de professores de IES que se reúnem anualmente para analisar se parte dessa produção recente foi estudada e incorporada por eles.

\title{
METODOLOGIA
}


Ao todo participaram da pesquisa $43^{4}$ professores representantes de ao menos uma Instituição de Ensino Superior Brasileira na condição de docente da disciplina de Handebol que participavam do II Encontro Nacional de Professores de Handebol, organizado pela $\mathrm{CBHb}$ na cidade de Foz do Iguaçu/PR em 2003.

Foi aplicado um questionário semi-estruturado (questões fechadas e abertas) contendo 10 perguntas nas quais, em seis questões, se necessário, permitiam a complementação das informações. Estes foram distribuídos no segundo dia do Encontro e recolhidos até o final do evento (quarto dia). Do total aproximado de 80 questionários entregues, 43 retornaram a nós preenchidos possibilitando nossa análise. Tal instrumento buscou levantar elementos que permitissem a caracterização dos traços gerais do perfil dos professores(as) e das disciplinas de handebol das instituições de ensino superior brasileiras, assim como saber qual/quais métodos de ensinoaprendizagem os mesmos utilizavam em suas aulas e quais os conteúdos foram ensinados. Caso tais professores lecionassem em mais de uma IES, foi sugerido que preenchessem as informações referentes à instituição que representavam naquele evento.

\section{RESULTADOS E DISCUSSÃO}

Nesta primeira etapa da apresentação dos resultados iremos explicitar a característica do corpo docente dos cursos analisados. Dos 43 professores que responderam ao questionário, 34 (correspondente a $79 \%$ ) já foram atletas de handebol antes de se dedicarem a carreira docente, conforme o gráfico 1 representado abaixo.

\footnotetext{
${ }^{4}$ Participaram deste evento 88 professores.
} 


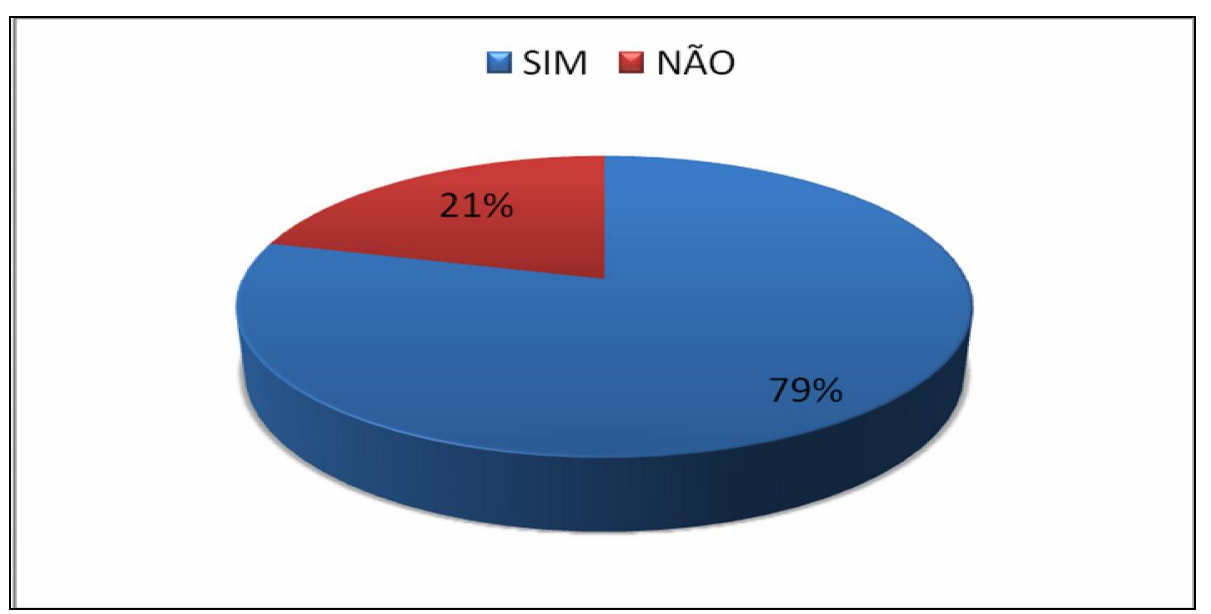

Gráfico 1: Percentual de professores que foram atletas de handebol.

Destes 43 professores, 18 possuem a titulação máxima de especialista (42\%), 20 a de mestre (46\%) e somente 5 docentes são doutores (12\%), conforme representado no gráfico 2. A grande maioria dos professores participantes deste estudo (especificamente 29 deles, aproximadamente 68\%) é vinculada às Instituições Privadas de Ensino Superior, enquanto que 13 (aproximadamente 30\%) deles às Instituições Públicas de Ensino Superior e somente um docente leciona em Instituições pública e privada (2\%), conforme representado no gráfico 3. A titulação dos docentes, assim como a natureza da instituição a que são vinculados estão representados respectivamente nos gráficos 2 e 3.

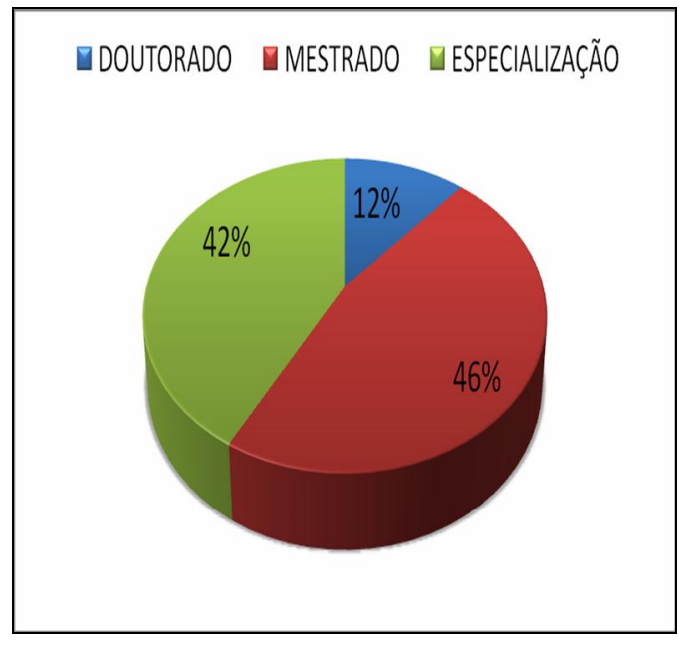

Gráfico 2: Titulação dos docentes em percentual.

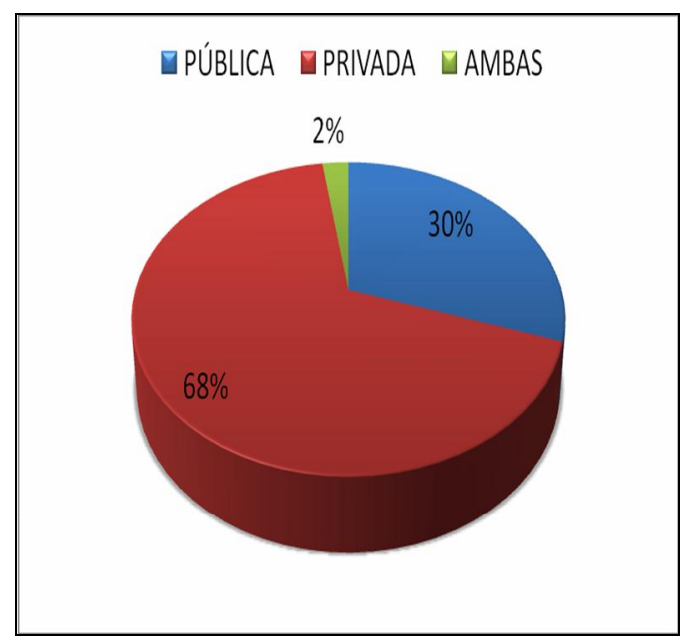

Gráfico 3: Natureza das instituições. 
Para finalizar esta primeira etapa de análise, nos deteremos à modalidade de curso curso que os professores lecionam, foi verificado, conforme o gráfico 4, que 30 professores (cerca de 70\%) lecionam no curso de licenciatura, um no curso de bacharelado e 12 (cerca de 28\%) ministram disciplinas de handebol tanto para a licenciatura quanto para o bacharelado, conforme representado no gráfico 4.

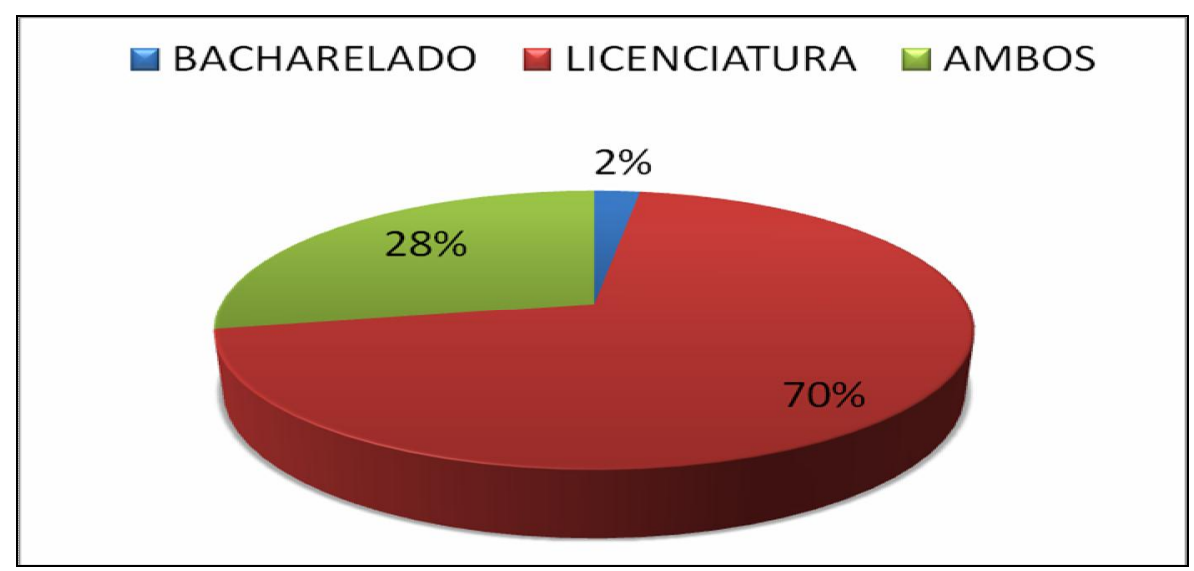

Gráfico 4: Percentual das modalidades de cursos em que são oferecidas as disciplinas de handebol.

Nesta segunda etapa de apresentação dos resultados iremos retratar as características das IES e as condições oferecidas por elas aos docentes para o desenvolvimento das disciplinas de Handebol. Focaremos os seguintes aspectos: a quantidade de disciplinas que cada professor oferece, o número de alunos matriculados por turma, as condições das instalações e a qualidade do material didático utilizado.

Como veremos a seguir, as disciplinas de handebol oferecidos nas IES diferem entre si em relação à quantidade de disciplinas oferecidas e horas destinadas para cada disciplina. Deste modo, como explicitado no gráfico 5, 28 professores (correspondentes a $65,2 \%$ do total) lecionam uma única disciplina de Handebol, 13 (30,2\%) lecionam duas disciplinas e somente dois professores $(4,6 \%)$ oferecem mais de duas disciplinas durante o curso, conforme pode ser observado no gráfico 5 . 


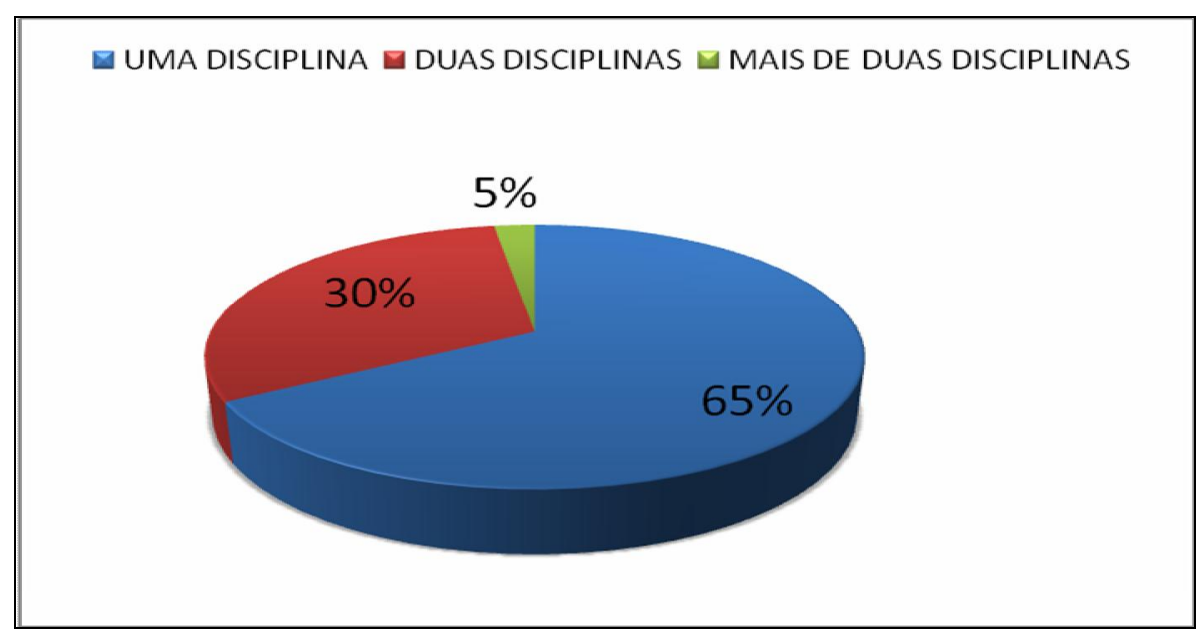

Gráfico 5: Quantidade de disciplinas oferecidas por cada professor nos cursos de handebol.

Quando levado em consideração apenas aqueles cursos em que são oferecidos somente uma disciplina e analisadas a sua carga horária, verificamos que somente dois cursos (cerca de 9\%) possuem uma carga horária inferior a 60 horas. Já a maior parcela dos cursos (14 que representam aproximadamente $61 \%$ do total analisado) oferece uma disciplina com carga horária que varia entre 60 e 68 horas. Outros $22 \%$ dos cursos analisados, que correspondem a cinco IES, possuem na sua única disciplina de handebol oferecida uma carga horária de 72 a 75 horas. Por fim, dois cursos (representando cada um somente $4 \%$ do total) apresentam uma carga horária de mais de 136 e 160 horas destinadas a uma única disciplina.

Por sua vez, quando considerados os cursos em que são oferecidos duas disciplinas obrigatórias de handebol e analisadas a sua carga horária constatamos que na maior parcela dos cursos (cerca de 38\%) a carga horária total destinada varia de 80 a 90 horas. Em menores proporções estão os cursos em que suas disciplinas possuem a carga horária de 105 a 120 horas (23\%), 144 horas (16\%), 160 horas (16\%) e 180 horas (7\%). O número de disciplinas de handebol oferecidas por cada professor nos cursos das IES e a quantidade de horas destinadas a cada disciplina nos cursos que possuem uma e naqueles que possuem duas disciplinas, estão representadas na tabela 1. 
TABELA 1 - Quantidade e porcentagem de carga horária total destinada aos cursos de Handebol que oferecem uma, duas ou mais de duas disciplinas.

\begin{tabular}{|c|c|c|}
\hline Disciplinas/Horas & & \\
\hline & QUAN & POR \\
\hline UMA DISCIPLINA OBRIGATÓRIA & & \\
\hline HORAS DEDICADAS AQUELES QUE LECIONAM UMA DISCIPLINA & 23 & $56 \%$ \\
\hline 40 a 54 & 2 & $9 \%$ \\
\hline 60 a 68 & 14 & $61 \%$ \\
\hline 72 a 75 & 5 & $22 \%$ \\
\hline 136 & 1 & $4 \%$ \\
\hline 160 & 1 & $4 \%$ \\
\hline HORAS DEDICADAS AQUELES QUE LECIONAM DUAS DISCIPLINA & 13 & $32 \%$ \\
\hline 80 a 90 & 5 & $38 \%$ \\
\hline 105 a 120 & 3 & $23 \%$ \\
\hline 144 & 2 & $16 \%$ \\
\hline 160 & 2 & $16 \%$ \\
\hline 180 & 1 & $7 \%$ \\
\hline DUAS DISCIPLINAS OBRIGATÓRIAS & & \\
\hline MAIS DE DUAS DISCIPLINAS OBRIGATÓRIAS & & \\
\hline 108 & 1 & $2 \%$ \\
\hline SOMAS DEDICADAS AQUELES QUE LECIONAM MAIS DE DUAS & 1 & $100 \%$ \\
\hline
\end{tabular}

Consideramos necessário para o ensino competente de um conteúdo mínimo de handebol voltado à formação de professores e profissionais de educação física no ensino superior, o oferecimento de ao menos 60 horas/aula. Sendo assim, averiguamos que, independente do fracionamento dos conteúdos de handebol em uma, duas ou mais disciplinas obrigatórias, a maioria das IES (cerca de 95\%) oferece uma carga mínima necessária para o trato do conhecimento historicamente produzido sobre handebol. Tendo em vista a luta contra a manutenção da EF escolar esportivizada travada pelas diversas correntes da Educação Física, a partir de meados da década de $1980^{5}$ e a incorporação de diversos outros conteúdos referentes à cultura corporal que não se limitam à prática esportiva, percebe-se que a configuração do ensino do

\footnotetext{
5 As produções mais representativas nesse sentido são Coletivo de autores (1992) e Hildebrandt e Laging, (1986).
} 
Handebol nas IES mostra-se ainda em situação adequado e num patamar desejável.

As tabelas 2 e 3 representadas a seguir mostram a quantidade mínima e máxima de alunos matriculados por turma. Cerca de 37\% daqueles analisados neste estudo, possui no mínimo de 21 a 30 alunos matriculados. Já em 30\% dos cursos o número mínimo de alunos matriculados varia de 11 a 20. Por sua vez, em relação ao número máximo de alunos matriculados por turma, a maior incidência se deu na escala de 35 a 48 alunos representando um percentual aproximado de 35\%. Se tirarmos uma média entre os valores mínimos e máximos de alunos por turma ela estará enquadrada numa escala de 30 a 46 alunos, ou seja, em média o número mínimo de alunos matriculados por turma é de 30 enquanto que o número máximo é de 46.

\begin{tabular}{|c|c|c|}
\hline \multicolumn{3}{|c|}{ MIN } \\
\hline & QUAN & POR \\
\hline 11 a 20 & 13 & $30 \%$ \\
\hline 21 a 30 & 16 & $37 \%$ \\
\hline 31 a 45 & 6 & $14 \%$ \\
\hline 50 a 70 & 7 & $17 \%$ \\
\hline Não respondeu & 1 & $2 \%$ \\
\hline
\end{tabular}

Tabela 2: Quantidade e percentual aproximado do número mínimo de alunos por turma.

\begin{tabular}{|c|c|c|}
\hline \multicolumn{3}{|c|}{ MAX } \\
\hline & QUAN & POR \\
\hline 25 a 30 & 7 & $17 \%$ \\
\hline 35 a 48 & 15 & $35 \%$ \\
\hline 50 a 59 & 10 & $23 \%$ \\
\hline 60 a 69 & 7 & $17 \%$ \\
\hline 70 a 80 & 3 & $6 \%$ \\
\hline Não respondeu & 1 & $2 \%$ \\
\hline
\end{tabular}

Tabela 3: Quantidade e percentual aproximado do número máximo de alunos por turma.

Consideramos ser necessário para o ensino de qualidade na formação de professores e profissionais de educação física em cursos lecionados por apenas um professor (sem auxiliares) turmas com 30 alunos, em média. As boas experiências no ensino superior comprovam a necessidade de uma grande atenção do professor nas aulas teórico-práticas discutindo com os alunos e avaliando a execução dos movimentos, assim como solicitando que os acadêmicos realizem observações críticas e debatam sobre as situações problemas do jogo, assim como sobre as possíveis escolhas táticas dos ñogadoresò etc. Queremos com isso dizer que no curso superior de educação física os alunos são ao mesmo tempo os executores (aprendizes) e os 
avaliadores dos diversos meios técnico-táticos das modalidades esportivas, assim como de todos os outros elementos do jogo coletivo.

Sendo assim, turmas de handebol com mais de 30 alunos, realidade de 35 cursos das IES analisadas (cerca de $83 \%$ ), são consideradas inadequadas em virtude do número elevado de alunos matriculados. Isso demonstra uma tendência de sucateamento do ensino já tão verificado nas escolas públicas paulistas de ensinos básico e médio desde a década de 1990 quando foram constituídas turmas de aulas de educação física com até 50 alunos por classe. Em Instituições de Ensino Superior particulares é comum a existência de turmas com 60, 70 ou até mais alunos como pode ser observado nos quadros 2 e 3 anteriormente expostos.

Quando questionados sobre as condições das instalações das Instituições de Ensino Superior onde oferecem as disciplinas de handebol, a grande maioria dos professores (cerca de 67\%) afirmou que as condições das instalações são adequadas, $14 \%$ muito adequada e $19 \%$ afirmou ser pouco adequada para o desenvolvimento pleno e qualificado das suas atividades. Acreditamos que aqueles que sinalizaram em suas respostas possuírem uma instalação em condição adequada ou muito adequada, contam nas suas IES com quadras oficiais de handebol $(40 \mathrm{~m} \times 20 \mathrm{~m})$, devidamente iluminadas quando necessário, uma biblioteca com literaturas diversificadas no âmbito do handebol e áreas correlatas, além de boas salas de aula equipadas com equipamentos de vídeo, internet e data show.

Em proporção semelhante estão as afirmações que buscaram retratar a qualidade do material didático utilizado no decorrer do curso. Mais da metade, exatamente $51 \%$ dos professores, julgou que o material didático que utiliza é adequado. Já $26 \%$ dos docentes afirmam ser muito adequado. Uma menor parcela, mas ainda significativa (cerca de $23 \%$ ), afirma que o material didático é pouco adequado. Os professores que afirmaram possuir um material didático adequado ou muito adequado (77\%), contam em seus cursos com bolas de handebol para as diversas categorias (de $\mathrm{H} 1$ à $\mathrm{H} 3$ ), bolas de iniciação esportiva e diversos materiais de apoio (tais quais cones, cordas, etc.), além de uma ampla literatura sobre o tema em sua biblioteca. 
As condições das instalações e a qualidade do material didático disponíveis para os professores estão representadas respectivamente nos gráficos 6 e 7.

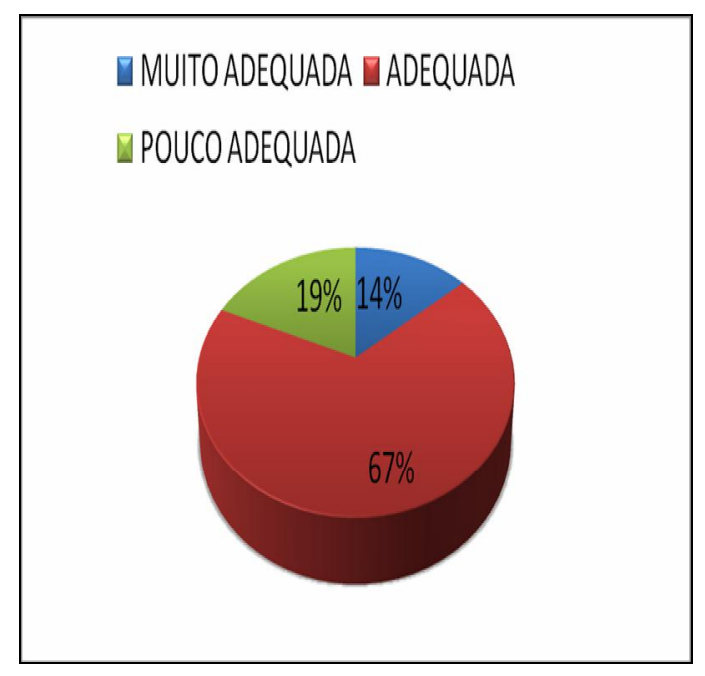

Gráfico 6: Condições das instalações das IES.

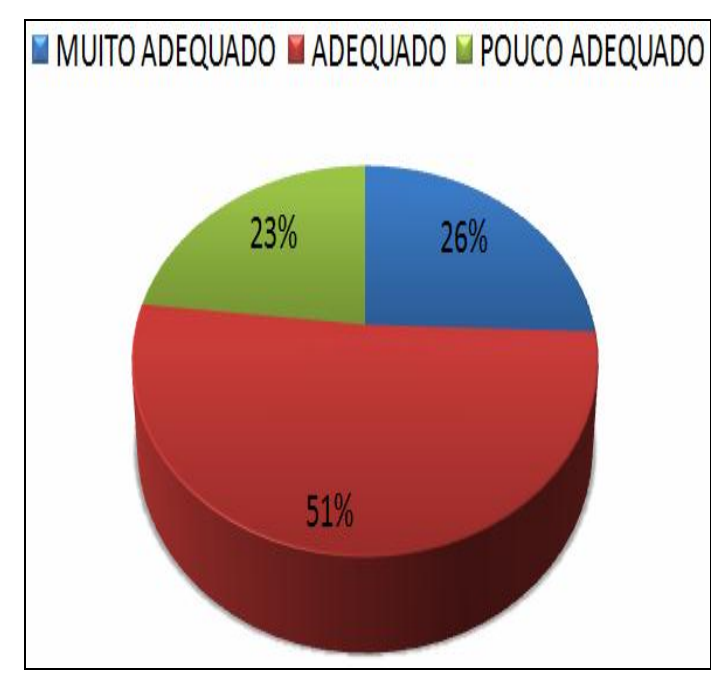

Gráfico 7: Qualidade do material didático utilizado.

Por fim, nesta terceira e última etapa de apresentação e discussão dos resultados iremos retratar o perfil das disciplinas de Handebol que são oferecidos pelos professores nas suas respectivas IES. Para tal finalidade explicitaremos os conteúdos referentes ao Handebol ensinados e os métodos de ensino utilizados pelos professores durante o curso.

Dentre os conteúdos ensinados, conforme retratado no gráfico 8 , foram mencionados pelos professores os fundamentos (passe, arremesso, recepção, drible, finta, empunhadura, progressão, defensivos e ofensivos). Tais fundamentos foram denominações dadas aos conteúdos técnicos das modalidades esportivas até a década de 1990, no Brasil. Entretanto, os avanços dos estudos, principalmente da psicologia, trouxeram novos elementos teóricos para o campo da educação física que possibilitaram mudanças significativas no entendimento da aprendizagem e do ensino dos esportes coletivos (GRECO, 1998; GARGANTA, 1995). Com a criação da área de pedagogia do esporte, esta passou a incorporar os novos conhecimentos ocasionando um descolamento das crenças anteriores, alicerçadas nos esportes individuais, que estavam consolidadas na educação física brasileira desde meados da segunda metade da década de 1940 quando os esportes 
coletivos foram introduzidos progressivamente como conteúdo escolar (BRACHT, 1986). Neste contexto, o handebol chega às escolas brasileiras na segunda metade da década de $1970 \mathrm{com}$ toda sua pratica pedagógica oriunda dos esportes individuais privilegiando primeiramente o domínio da técnica para depois sua prática de modo global (REIS, 1994). Sendo assim, fundamento é a denominação histórica dada aos gestos técnicos em cada modalidade esportiva, que começa a perder força na área a partir dos primeiros anos do século XXI.

Porém, como estavam sendo apresentadas, as novas produções que deram origem a criação de uma nova área, a da pedagogia do esporte, as produções trouxeram para o nosso campo a denominação de meios técnicotáticos em substituição aos fundamentos e a ampliação do conceito do que é mais importante na aprendizagem inicial dos esportes coletivos. A argumentação para tal mudança se sustenta, tratando-se de uma modalidade coletiva, na obrigatoriedade em se partir do pressuposto que é preciso resolver um problema apresentado e imprevisível, ou seja, é necessário decidir o que fazer em determinadas situações apresentadas no jogo e para tal o mais adequado é se pensar em meios técnicos que solucionem uma questão tática. Por isso a denominação de meio técnico-tático. O como fazer passou a ser subjetivo, pois sem saber o que resolver, parece desnecessário a exatidão do gesto (GARGANTA, 1995).

O processo de ensino-aprendizagem se sustenta na medida em que é realizado através de um planejamento consciente e variado permitindo ao aprendiz a fixação dos conteúdos e a sua melhora do nível de aptidão (GRECO, 2001). Ou seja, o planejamento deve se aproximar da quantificação das variáveis e de suas alterações nas diversas situações do jogo tornando o desenvolvimento dessas aptidões mais individualizadas e eficazes (MENEZES e REIS, 2010).

Ainda apareceram como conteúdos ensinados nas disciplinas de handebol os meios táticos ofensivos e defensivos, sistemas defensivos e ofensivos, periodização, mini handebol, handebol de praia, regras e histórico. 
Quase todos esses conteúdos mencionados, com exceção do handebol de praia $^{6}$, são necessários e estão considerados como mínimos no curso superior.

Entre os fundamentos citados, o passe e o arremesso estiveram presentes na maioria das respostas, representando respectivamente $60 \%$ e $57 \%$ do total. Outros fundamentos também bastante mencionados pelos professores foram a recepção (45\%) e o drible (45\%). Em menor proporção surgiram a empunhadura (cerca de $7 \%$ ) e o ritmo trifásico (2\%). Nenhum dos 43 participantes da pesquisa citou o duplo ritmo trifásico como fundamento trabalhado ao longo da disciplina de handebol, como este recurso é esta presente na literatura e é utilizado com frequência em jogos, pode-se apreender que os nossos pesquisados não utilizam essa denominação ou não consideram este um fundamento. No entanto, é preciso ressaltar que oito professores (equivalente a 19\%) afirmaram trabalhar todos os fundamentos (não detalhando quais) e três sinalizaram somente que os fundamentos estão entre os conteúdos desenvolvidos, mas não especificaram quais.

Quando sugerido que especificassem os fundamentos trabalhados, foram mencionados pelos professores o passe, arremesso, recepção, drible, empunhadura e ritmo trifásico, conforme retratado no gráfico 8.

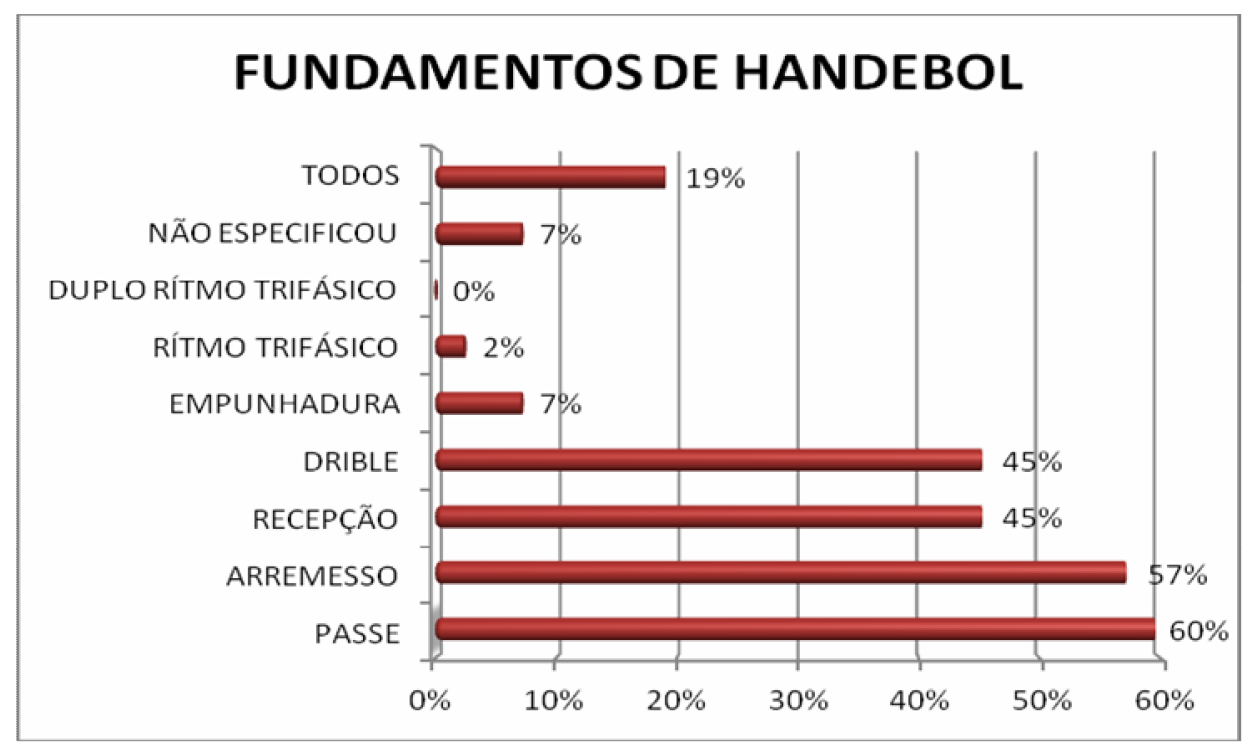

Gráfico 8: Porcentagem dos conteúdos ensinados nas disciplinas de handebol nas IES.

\footnotetext{
${ }^{6}$ Apesar da $\mathrm{CBHb}$ em seus encontros anuais apelar para que os professores de handebol tratem esse conteúdo em suas disciplinas, a consideramos uma outra modalidade esportiva.
} 
Um ponto que merece nossa atenção refere-se às denominações dadas pelos professores aos fundamentos do handebol. A finta, por exemplo, apesar de estar presente em $43 \%$ das respostas, não é considerado pela literatura (Menezes, 2011; Antón García, 1990) um fundamento, por entendê-la como um meio tático ofensivo. O mesmo aconteceu com a progressão, citada por $12 \%$ dos docentes.

Em menor proporção foram citados como fundamentos: o desarme, o bloqueio, o posicionamento defensivo, a marcação, o manejo de bola, os giros, os lançamentos, entre outros. Os fundamentos denominados pelos professores participantes da pesquisa em defensivos e ofensivos, juntos, somaram 10\% das respostas. Se considerarmos que não há na literatura a denominação de fundamentos ofensivos e defensivos, este índice pode ser considerado elevado e preocupante. Elevado porque se espera que uma grande parcela, preferencialmente todo o corpo docente, compreenda a diferenciação entre fundamentos, meios táticos ofensivos e defensivos e sistemas ofensivos e defensivos. Portanto, não há a diferenciação dos fundamentos em ofensivos e defensivos, já que devem ser tratados como um único conteúdo e trabalhados em situações ofensivas no handebol. Neste ponto, vale ressaltar que a empunhadura, citada pelos professores, também é considerado pela literatura um fundamento (RIBEIRO, s/d; REIS, 2006). Mais recentemente, todos os fundamentos, tais como: a empunhadura, o passe, a recepção, o drible, o arremesso, o ritmo trifásico e o duplo ritmo trifásico (esse último não apareceu nas respostas) são denominados de elementos ou meios técnico-táticos. Preocupante, porque estas denominações e compreensão acerca dos fundamentos do handebol são transmitidos pelos professores das disciplinas de handebol das IES aos alunos de graduação em Educação Física que irão reproduzir, quando formados, seu aprendizado para milhares de crianças e jovens, por meio da sua prática pedagógica.

Por fim, nesta última etapa de análise, iremos nos deter aos métodos de ensino utilizados pelos professores durante as disciplinas de handebol ministrados nas IES brasileiras. O gráfico abaixo nos auxilia na visualização da significativa superioridade de citações dos métodos Misto e Iniciação Esportiva Universal (IEU). 


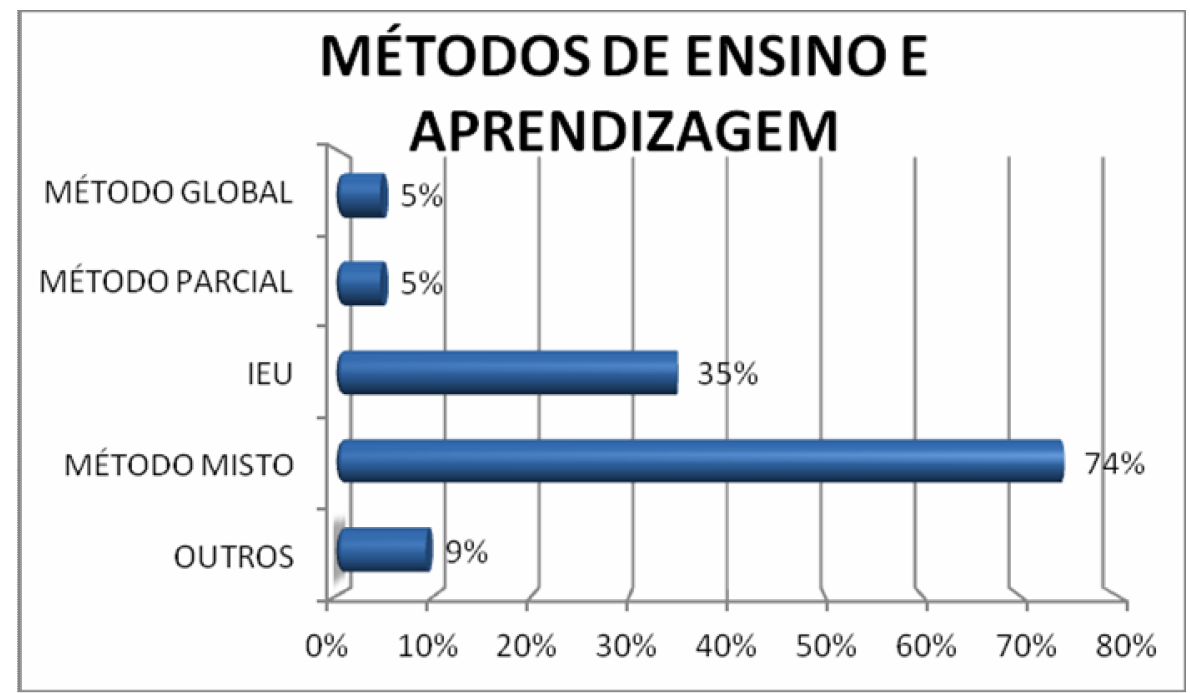

Gráfico 9: Porcentagem dos métodos de ensino adotados nos cursos de handebol nas IES.

A partir do gráfico 9 foi possível observar que a grande maioria dos professores (cerca de 74\%) adota o método de ensino Misto na disciplina que leciona. Por sua vez, o método da Iniciação Esportiva Universal (IEU) proposto por Greco (1998), aparece como o segundo mais utilizado estando presente em $35 \%$ das respostas. Apesar da maior presença dos métodos Misto e IEU, salientamos que todos possuem vantagens e desvantagens, cabendo ao professor adotar por um método que melhor se adéque aos seus objetivos, necessidades e às características bio-psico-social do grupo que se propõe trabalhar (REIS, 2006).

\section{CONCLUSÕES}

Ao término desta pesquisa pudemos concluir que a relação entre a vida esportiva e profissional dos professores de handebol das IES é significativa, ou seja, a maioria dos professores de handebol da IES brasileiras foram handebolistas. Suas experiências obtidas como atleta de handebol certamente contribuem tanto para o conhecimento adquirido quanto para o gosto $\mathrm{e}$ interesse de lecionar disciplinas acerca desta modalidade esportiva. Porém, apenas a experiência de atletas não é suficiente para a docência do handebol no ensino superior. A maior parte dos professores entrevistados (cerca de $88 \%$ ) possui a titulação de especialista ou mestre, o que nos remete à necessidade de ampliar a presença de docentes com a titulação de doutor 
nessas IES, já que este é um requisito do Ministério da Educação para a aprovação de novos cursos em IES no Brasil. Ainda assim, o fato de tais professores estarem representando em parcela significativa as IES particulares, por um lado nos alerta em relação à pequena presença de representantes de Instituições públicas neste Encontro, por outro retrata a vasta quantidade de IES particulares pelo Brasil, principalmente quando comparadas com as públicas. Neste aspecto, os dados trazidos pelo Observatório do Esporte $^{7}$ ratificam a superioridade de IES particulares em relação às públicas, na ordem de $70 \%$.

Quando analisadas as características e o perfil das disciplinas de handebol nas IES brasileiras vimos que aquelas analisadas neste estudo diferem entre si em relação a uma série de fatores. A maior parte delas oferece durante o curso uma única disciplina de handebol, sendo que somente em dois cursos a carga horária é abaixo da considerada por nós como a ideal para o ensino do conteúdo mínimo de handebol, ou seja, a dedicação de 60 horas $^{8}$. Turmas com 30 alunos matriculados, número compreendido por nós ${ }^{9}$ como mais adequado para o ensino de qualidade, estão presentes em somente 17\% das IES analisadas, fato que nos preocupa ainda mais quando nos deparamos com turmas de até 80 alunos. Por outro lado, tanto as instalações quanto os materiais didáticos disponíveis foram apontados pela grande maioria dos professores como adequados ou muito adequados, fato que no nosso entendimento contribui significativamente para o oferecimento de um curso de qualidade.

No entanto, os dados que merecem maior preocupação referem-se aos conteúdos e métodos de ensino adotados pelos docentes. A percepção de que há entre os professores um desconhecimento das novas produções, de qualidade, no campo da pedagogia do esporte, verificada principalmente a

\footnotetext{
${ }^{7}$ Consultar: www.observatoriodoesporte.org.br

${ }^{8}$ Essa consideração não é aleatória faz parte da conclusão de longos debates da comunidade acadêmica (inclusive nos encontros de professores de IES da $\mathrm{CBHb}$ ), especialista em handebol acumulados ao longo do tempo e que até o momento não foi tomada seriamente como objeto de pesquisa no campo. O que se pretende neste artigo é iniciar publicações com esse tema.

${ }^{9}$ Idem a nota anterior.
} 
partir do emprego de termos não mais utilizados, assim como da implementação de metodologias de ensino de modo pouco clara e coerente, nos remete à necessidade de ampliar a formação continuada e a busca por novas produções no subcampo handebol. Neste aspecto, corroboramos nossas afirmações com as realizadas por Souza (2007), visto que em ambas as pesquisas foram detectadas incoerências por parte dos docentes quanto à metodologia utilizada e principalmente em relação à dificuldade de se posicionar ou definir questões importantes referentes a disciplina que ministra e ao desconhecimento de novos estudos.

Sendo assim, ressaltamos novamente a importância da continuidade da realização do Encontro Nacional de Professores de Handebol das Instituições de Ensino Superior a fim de qualificar esse processo de atualização teórica e formação continuada dos docentes com a consequente melhora no perfil das disciplinas de handebol da IES brasileiras. Apontamos, ainda, para a necessidade de realização de novas pesquisas com a observação de aulas das IES brasileiras, assim como a realizada por Souza (2007), para produzir um amplo conhecimento da realidade do ensino do handebol e provocar uma reflexão e discussão do subcampo handebol a fim de que os conhecimentos produzidos e ensinados sejam de acesso do grande público de alunos de cursos superiores de educação física no Brasil.

\section{REFERÊNCIAS}

ANTÓN GARCÍA, J. L. Balonmano: fundamentos y etapas de aprendizaje. Madrid: Gymnos Editorial, 1990.

BRACHT, Valter. Educação Física: A busca da autonomia pedagógica. Revista da Fundação de Esporte e Turismo 1(2). p.12-19, 1989.

COLETVO DE AUTORES. Metodologia do Ensino da Educação Física. São Paulo: Cortez, 1992.

GARGANTA, J. Para uma teoria dos jogos desportivos colectivos. In: Graça A, Oliveira J.(Ed.) O Ensino dos Jogos Desportivos. Porto: Faculdade de Ciências do Desporto e de Educação Física. Porto: Centro de Estudos dos Jogos Desportivos, 1995, 2ª ed., p. 11-25. 
GRECO, P.J. Iniciação Esportiva Universal 1. Belo Horizonte: Ed. UFMG, 1998.

GRECO, P.J. Métodos de ensino-aprendizagem-treinamento nos jogos esportivos coletivos. In: Garcia ES, Lemos KLM. Temas Atuais VI em Educação Física e Esportes. Belo Horizonte: Saúde Ltda., 2001, p.48-72.

MENEZES, R.P. Modelo de análise técnico-tática do jogo de handebol: necessidades, perspectivas e implicações de um modelo de interpretação das situações de jogo em tempo real. Universidade Estadual de Campinas, Faculdade de Educação Física. Tese de Doutorado, 2011.

MENEZES, R. P.; REIS, H. H. B. Análise do jogo de handebol como ferramenta para compreensão técnico-tática. Motriz (Rio Claro) (Cessou em 2006), v. 16, p. 458-467, 2010.

HILDEBRANDT, Reiner; LAGING, Ralf. Concepções abertas no ensino da Educação Física. Rio de Janeiro. Ao livro Técnico, 1986.

REIS, H.H.B. O ensino dos jogos coletivos esportizados na escola. Dissertação (Mestrado em Educação Física) Universidade Federal de Santa Maria, 1994.

0 ensino do handebol utilizando-se do método parcial. http://www.efdeportes.com/ Revista Digital - Buenos Aires - Año 10 - № 93 ï Fev, 2006.

RIBEIRO, Valdir. Manual de handebol. Aracatuba: LEME, s/d.

SOUZA, N. P. O ensino das disciplinas esportivas coletivas nos cursos de licenciatura em Goiás: um estudo descritivo. Tese (Doutorado) - Faculdade Educação Física, Universidade Estadual de Campinas, Campinas, 2007.

\title{
THE PROFILE OF HANDBALL COURSES ON COLLEGE INSTITUTIONS
}

\begin{abstract}
The objective of this paper is to present a survey on the profile of handball courses offered by higher education institutions in Brazil from the perspective of their teachers. We administered a questionnaire containing 10 questions. Contained the same elements that allow to characterize the general features of the profile of teachers and handball courses. The results showed that the majority of the 43 teachers played handball, have specialist training or teach in the masters and undergraduate programs. The profiles of the courses differ in a number of aspects: number of disciplines, working hours, enrolled students, content taught and teaching methods. The research confirms the importance and necessity for refresher courses for the public.
\end{abstract}


Keywords: Profile of Teachers Handball and knowledge addressed in initial training; Handball, Vocational training; degree in Physical Education;

\section{EI PERFIL DE LAS ASIGNATURAS DE BALONMANO DE LAS INSTITUICIONES DE EDUCACIÓN SUPERIOR}

\section{RESUMEN}

El objetivo de este trabajo es presentar una investigación sobre el perfil de las asignaturas de balonmano que ofrecen las instituciones de educación superior en Brasil desde la perspectiva de sus maestros. Se administró un cuestionario de 10 preguntas. Contenía los mismos elementos que permiten caracterizar los rasgos generales del perfil de los maestros y las asignaturas de balonmano. Los resultados mostraron que la mayoría de los 43 profesores han sido jugadores de balonmano, tienen una formación especializada en ese deporte 0 son post graduados en cursos de masters y de licenciatura. Los perfiles de los cursos se diferencian en varios aspectos: número de disciplinas, las horas de trabajo, los estudiantes matriculados, los contenidos enseñados y los métodos de enseñanza. La investigación confirma la importancia y la necesidad de cursos de actualización para ese público.

Palabras clave: Perfil de Profesores de Balonmano y el conocimiento se dirigió en la formación inicial; Balonmano, la formación profesional, licenciado en Educación Física;

\section{Endereço para correspondência:}

Heloisa Helena Baldy Reis

E-mail: helobaldy@yahoo.com 